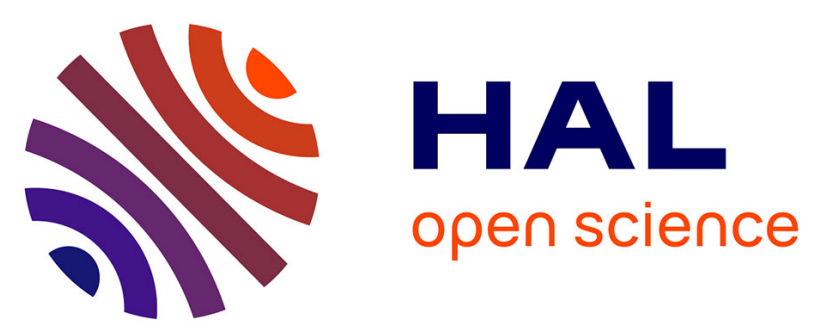

\title{
Comparison of Outcomes and Mortality in Patients Having Left Ventricular Assist Device Implanted Early -vs- Late After Diagnosis of Cardiomyopathy
}

Elisabeth Chen, Nicolas Nesseler, Raphaël Martins, Céline Goéminne, André Vincentelli, Clément Delmas, Jean Porterie, Karine Nubret, Mathieu Pernot, Michel Kindo, et al.

\section{To cite this version:}

Elisabeth Chen, Nicolas Nesseler, Raphaël Martins, Céline Goéminne, André Vincentelli, et al.. Comparison of Outcomes and Mortality in Patients Having Left Ventricular Assist Device Implanted Early -vs- Late After Diagnosis of Cardiomyopathy. American Journal of Cardiology, 2021, 146, pp.82-88. 10.1016/j.amjcard.2021.01.027 . hal-03135802

\section{HAL Id: hal-03135802 https://hal.science/hal-03135802}

Submitted on 9 Mar 2021

HAL is a multi-disciplinary open access archive for the deposit and dissemination of scientific research documents, whether they are published or not. The documents may come from teaching and research institutions in France or abroad, or from public or private research centers.
L'archive ouverte pluridisciplinaire HAL, est destinée au dépôt et à la diffusion de documents scientifiques de niveau recherche, publiés ou non, émanant des établissements d'enseignement et de recherche français ou étrangers, des laboratoires publics ou privés. 


\section{Comparison of Outcomes and Mortality in Patients Having Left Ventricular Assist Device Implanted Early -vs- Late After Diagnosis of Cardiomyopathy}

Running title: LVAD for recently diagnosed cardiomyopathy

Authors: Elisabeth Chen, MD, ${ }^{a}$ Nicolas Nesseler, MD, PhD, ${ }^{a}$ Raphaël P. Martins, $\mathrm{MD}, \mathrm{PhD},{ }^{\mathrm{a}}$ Céline Goéminne, MD, ${ }^{\mathrm{b}}$ André Vincentelli, MD, PhD, ${ }^{\mathrm{b}}$ Clément Delmas MD, ${ }^{c}$ Jean Porterie, MD, ${ }^{c}$ Karine Nubret, MD, ${ }^{d}$ Mathieu Pernot, MD ${ }^{d}$ Michel Kindo, $\mathrm{MD}, \mathrm{PhD},{ }^{\mathrm{e}}$ Tam Hoang Minh, MD, ${ }^{\mathrm{e}}$ Philippe Gaudard, MD, ${ }^{\dagger}$ Philippe Rouvière, MD, ${ }^{\dagger}$ Magali Michel, MD, ${ }^{\mathrm{h}}$ Thomas Sénage, MD, ${ }^{\mathrm{h}}$ Aude Boignard, MD, Olivier Chavanon, MD, PhD, ${ }^{i}$ Constance Verdonk, MD, ${ }^{j}$ Marylou Para, MD, ${ }^{j}$ Edeline Pelcé, MD, ${ }^{k}$ Vlad Gariboldi, MD, PhD, ${ }^{k}$ Matteo Pozzi, MD,' Guillaume Baudry, MD,' Pierre-Yves Litzler, $\mathrm{MD}, \mathrm{PhD}^{\mathrm{m}}$ Frédéric Anselme, $\mathrm{MD},{ }^{\mathrm{m}}$ Katrien Blanchart, $\mathrm{MD},{ }^{\mathrm{n}}$ Gerard Babatasi, MD, $\mathrm{PhD},{ }^{\mathrm{n}}$ Fabien Garnier, MD, ${ }^{\circ}$ Marie Bielefeld, MD, ${ }^{\circ}$ Costin Radu, MD, ${ }^{\mathrm{p}}$ Nicolas Lellouche, MD, PhD, ${ }^{p}$ Thierry Bourguignon, MD, ${ }^{q}$ Thibaud Genet MD, ${ }^{q}$ Romain Eschalier, MD, PhD, ${ }^{r}$ Nicolas D'Ostrevy, MD, ${ }^{r}$ Marie-Cécile Bories, MD, ${ }^{\mathrm{r}}$ Pierre Baudinaud, MD, ${ }^{\mathrm{s}}$ Fabrice Vanhuyse, MD, ${ }^{\mathrm{t}}$ Hugues Blangy, MD, ${ }^{\mathrm{t}}$ Christophe Leclercq, $\mathrm{MD}, \mathrm{PhD},{ }^{\mathrm{a}}$, Erwan Flécher, $\mathrm{MD}, \mathrm{PhD},{ }^{\mathrm{a}}$ Vincent Galand, $\mathrm{MD},{ }^{\mathrm{a}}$

AFFILIATIONS. 'Univ Rennes, CHU Rennes, INSERM, LTSI - UMR 1099, F-35000 Rennes, France; ${ }^{\mathrm{b}} \mathrm{CHU}$ Lille, Institut Coeur-Poumons, Cardiac Intensive Care Unit, Department of Cardiology, Department of Cardiac Surgery, Lille, France; 'Centre Hospitalier Universitaire de Toulouse, Toulouse, France; 'Hôpital Cardiologique du Haut-Lévêque, LIRYC institute, Université Bordeaux, Bordeaux, France; ${ }^{e}$ Département de chirurgie cardiovasculaire, hôpitaux universitaires de Strasbourg, Strasbourg, France; 'Department of Anesthesiology and Critical Care Medicine, PhyMedExp, University of Montpellier, INSERM, CNRS, CHU Montpellier, Montpellier, France; 'Department of Cardiac Surgery, Anesthesiology and Critical Care Medicine, Arnaud de Villeneuve Hospital, CHRU Montpellier, Montpellier,

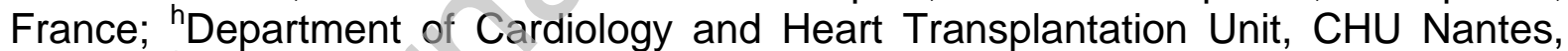
France; 'Department of Cardiology and Cardiovascular Surgery, CHU Michallon, Grenoble, France; 'Department of Cardiology and cardiac surgery, Bichat-Hospital, Paris, France; ${ }^{k}$ Department of Cardiac Surgery, La Timone Hospital, Marseille, France 'Department of Cardiac Surgery, "Louis Pradel" Cardiologic Hospital, Lyon, France; ${ }^{m}$ Department of Cardiology and Cardiovascular Surgery, Hospital Charles Nicolle, Rouen, France; ${ }^{\text {n}}$ Department of Cardiology and Cardiac Surgery, University of Caen and University Hospital of Caen, France; ${ }^{\circ}$ Department of Cardiology and cardiac surgery, University Hospital, Dijon, France; 'PDepartment of Cardiology and Cardiac Surgery, AP-HP CHU Henri Mondor, Créteil, France; ${ }^{9}$ Department of Cardiology and Cardiac Surgery, Tours University Hospital, Tours, France; ' $\mathrm{CHU}$ Clermont-Ferrand, Cardiology Department, Clermont-Ferrand, France; ${ }^{s}$ European Georges Pompidou Hospital, Cardiology Department, Paris, France; 'Department of Cardiology and Cardiac Surgery, CHU de Nancy, Hopital de Brabois, Nancy, France.

CORRESPONDING AUTHOR Vincent Galand, Service de Cardiologie et Maladies Vasculaires, CHU de Rennes, 2 rue Henri Le Guilloux, 35000 Rennes, France. Tel: + 33299282 507, Fax: +33 299282 529, E-mail: vincent.galand35@gmail.com 


\section{Abstract}

LVAD implantation in patients with a recently diagnosed cardiomyopathy has been poorly investigated. This work aims at describing the characteristics and outcomes of patients receiving a LVAD within 30 days following the diagnosis of cardiomyopathy. Patients from the ASSIST-ICD study were divided into recently and remotely diagnosed cardiomyopathy based on the time from initial diagnosis of cardiomyopathy to LVAD implantation using the cut point of 30 days. The primary endpoint of the study was all-cause mortality at 30-days and during follow-up. A total of 652 patients were included and followed during a median time of $9.1(2.5-22.1)$ months. Among this population, $117(17.9 \%)$ had a recently diagnosed cardiomyopathy and had LVAD implantation after a median time of 15.0 (9.0-24.0) days following the diagnosis. This group of patients was significantly younger, with more ischemic cardiomyopathy, more sudden cardiac arrest (SCA) events at the time of the diagnosis and were more likely to receive temporary mechanical support prior to LVAD compared to the remotely diagnosed group. Post-operative in-hospital survival was similar among groups, but recently diagnosed patients had a better long-term survival after hospital discharge. SCA prior to LVAD and any cardiac surgery combined with LVAD implantation were identified as two independent predictors of post-operative mortality in recently diagnosed patients. In conclusion, rescue LVAD implantation for recently diagnosed severe cardiomyopathy is common in clinical practice. Such patients experience a relatively low post-operative mortality and have a better long-term survival compared to remotely diagnosed patients.

Key words: Recently diagnosed cardiomyopathy, remotely diagnosed cardiomyopathy, LVAD implantation, survival. 


\section{Introduction}

Heart failure (HF) remains associated with high morbidity and mortality, especially in patients hospitalized for acute HF. Recent data have shown that patients with acute $\mathrm{HF}$ have a 4 -fold higher risk of 1 -year mortality than those with chronic HF, suggesting that these patients should be carefully managed (1). Left ventricular assistance device (LVAD) therapy improves survival in HF patients and is often implanted in chronic cardiac disease (1-2). Conversely, data about LVAD implantation at the acute stage of new-onset HF in patients with recently diagnosed cardiomyopathy are scarce and limited to small cohorts (3-5). Indeed, a cardiomyopathy may sometimes be diagnosed at the critical stage of severe de novo acute HF with cardiogenic shock and heart transplantation remains the best therapeutic option. However, due to restricted donors, rescue LVAD implantation may represent an interesting alternative. This study aims at investigating the characteristics and outcomes of patients urgently implanted with a LVAD for a recently diagnosed cardiomyopathy.

\section{Methods}

This study is based on the ASSIST-ICD study, a retrospective multicenter observational study (NCT02873169) of durable mechanical circulatory support devices implanted in 19 tertiary French centers. Patients $\geq 18$ years of age who had been implanted with axial HeartMate II (Abbott, Chicago, Illinois), Jarvik 2000 (Jarvik Heart, New York, New York), or centrifugal HeartWare pumps (Medtronic, Columbia Heights, Minnesota) between February 2006 and December 2016 were included. Exclusion criteria were patients undergoing total artificial heart placement or pulsatile-flow LVAD, history of heart transplant, death or heart transplantation before 
discharge from hospital after LVAD implantation, and VentrAssist (Ventracor, Chatswood, Australia) recipients. Details on the ASSIST-ICD database have been previously described (6). This study was approved by the regional ethic committees, the French Advisory Committee on the Treatment of Research Information in the Field of Health, and the French National Commission of Informatics and Civil Liberties.

Baseline data-including demographic characteristics, cardiac disease and heart failure history, supraventricular arrhythmia, other temporary mechanical support before LVAD implantation history, echocardiography, and blood chemistry values-were collected from hospital files for all enrolled patients. The echocardiographic and blood sample data used for the analysis were the last performed before LVAD implantation. Follow-up was performed according to each center's usual practice. The last day of follow-up was December 31, 2016; the date of heart transplantation; or death, whichever occurred first.

For the purpose of this study, the overall population was divided into recently and remotely diagnosed cardiomyopathy based on the time from initial diagnosis of cardiomyopathy to LVAD implantation using the cut point of 30 days. The primary endpoint of the study was all-cause mortality during follow-up. Deaths were classified as cardiovascular death (cardiac or vascular cause), non-cardiac death, or unknown cause. Secondary endpoints included heart transplantation and LVAD related complications (i.e. thrombosis, stroke, bleeding, and LVAD malfunction) in the 30 days post-operative period and during long-term follow-up.

Qualitative variables are expressed as number (percentage); continuous data as mean \pm standard deviation or median (interquartile range (IQR)) depending on their distribution, which was assessed using the Kolmogorov-Smirnov test. Survival rates were summarized using Kaplan-Meier estimates, and log-rank tests were used 
to compare groups. Predictors of post-operative mortality and long-term mortality were analyzed using univariate and multivariable proportional hazard models (cumulative outcomes). The proportional hazard assumption was tested and verified for each covariate. Variables with $p$-values $<0.05$ in univariate analysis were included in the multivariable analysis. Statistical analyses were conducted using the Statistical Package for Social Sciences version 22 (SPSS Inc., IBM, Armonk, New York).

\section{Results}

Among 652 patients implanted with a LVAD, 117 (17.9\%) were implanted during the first 30 days after the diagnosis of the cardiomyopathy and were considered as "recently diagnosed" cardiomyopathy. The median time between diagnosis and implantation was 15.0 (IQR: 9.0-24.0, from 2 to 30 days) days. Figure 1 shows the underlying etiologies. Notably, the main etiology of de novo acute HF was acute myocardial infarction (74\%). Baseline characteristics of the study population are described in Table 1. Briefly, the "recently diagnosed" group was significantly younger, with a lower body mass index (BMI), had more ischemic cardiomyopathy, and more sudden cardiac arrest (SCA) events at the time of diagnosis. Notably, they had a less dilated left ventricle but worst left ventricular ejection fraction (LVEF) at the time of LVAD implantation. Importantly, the recently diagnosed group received significantly more temporary mechanical support prior to LVAD but had better renal function at the time of the LVAD surgery. Additionally, they were more likely implanted as bridge to transplantation or bridge to decision/recovery.

During the post-operative period (i.e. $<30$ days post-operative period), a total of $16(13.7 \%)$ and $101(18.9 \%)$ patients died in the recently and remotely diagnosed 
LVAD groups, respectively. As shown in Table 2, the causes of death were mostly non-cardiovascular, and similar among groups. Figure 2 summarizes the causes of death in the recently diagnosed group, predominantly due to mesenteric ischemia, cerebral bleeding, respiratory and multi-organ failure, or right ventricular failure.

The baseline characteristics between survivors $(n=101,86.3 \%)$ and deceased $(n=16,13.7 \%)$ in the recently diagnosed group are described in Table 3 . Briefly, patients who died had more impaired LVEF and renal function at baseline, more history of SCA at the time of diagnosis, were more frequently implanted as destination therapy and had more cardiac surgery combined with LVAD implantation. Temporary mechanical support prior to LVAD implantation did not differ among groups. In multivariable analysis, SCA prior to LVAD and any cardiac surgery combined with LVAD implantation were identified as two independent predictors of post-operative mortality (Table 4). Figure 3 illustrates post-operative survival depending on the number of predictors. Interestingly, patients with no predictors were at low risk of post-operative death, those with only 1 predictor were at intermediate risk of death and LVAD recipients with 2 predictors were at high risk of death with only a $40 \%$ survival rate at 30 -days post-operative.

After 9.1 (2.5-22.1) months of follow-up, a total of $47(40.2 \%)$ and $152(28.4 \%)$ patients were heart transplanted $(p=0.017)$ and $38(32.5 \%)$ and $253(47.3 \%)$ LVAD recipients died $(p=0.005)$ in the recently and remotely diagnosed cardiomyopathy groups, respectively (Table 2). Both groups had similar survival rates in the postoperative period (Figure 4, panel A). However, among patients discharged alive from hospital, the recently diagnosed group had better mid-term survival (Figure 4, panel B). Interestingly, there was no difference regarding LVAD related complications during long-term follow-up. Additionally, $5(4.3 \%)$ patients in the 
recently diagnosed group eventually had LVAD removal as a consequence of myocardial recovery (1 patient with ischemic heart disease, 1 with beta-blocker intoxication and 3 with idiopathic dilated cardiomyopathies). Conversely, no patient in the remotely diagnosed group was explanted for myocardial recovery.

\section{Discussion}

The main results of this study focusing on LVAD implantation in patients recently diagnosed with a cardiomyopathy are as follows : 1) LVAD implantation within 30 days after the diagnosis of a cardiomyopathy is not uncommon, representing $17.9 \%$ of the LVAD implantations ; 2) These patients experience a good post-operative survival, with a 30-day mortality incidence of $13.7 \%$, and have a better long-term survival after hospital discharge compared to remotely diagnosed patients ; 3) SCA prior to LVAD and any cardiac surgery combined with LVAD implantation are two independent predictors of post-operative mortality in this subgroup of patients.

The most common etiology remains cardiac ischemia leading to decreased myocardial contractility and potentially life threatening hemodynamic situation (7). Furthermore, non-ischemic myocardial insults (inflammatory, toxic or peri-partum) represent potential other causes of acute HF. De novo acute HF may also be the first expression of an underlying idiopathic dilated cardiomyopathy thus far asymptomatic. Importantly, it has been shown that de novo HF is associated with poor outcomes, especially in patients with HF complicating myocardial infarction who are at high risk of in-hospital death (8). Similarly, in patients experiencing de novo HF with inaugural refractory cardiogenic shock, mortality is high with $>50 \%$ of inhospital death (9). 
LVAD implantation in the acute period following the diagnosis of de novo cardiomyopathy has been poorly investigated thus far. In a small US cohort including a total of 13 patients with recent myocardial infarction and refractory cardiogenic shock, LVAD as a rescue strategy was implanted between 1 and 23 days following myocardial infarction with a 1-year survival rate of $86 \%$, (3). More recently, Pawale et al. described a more aggressive strategy with an emergency durable LVAD implantation within the 24 hours following the diagnosis of the cardiomyopathy in a cohort of 43 refractory cardiogenic shock patients (5). In this study, authors reported a 74\% 1-year mortality. Conversely, we did not enrolled patients scheduled for LVAD in alternative to temporary mechanical support but only refractory HF patients receiving LVAD as a rescue strategy. We confirm the positive results previously described, with a post-operative survival at 30 days of $87 \%$. Our results suggest that this strategy may be an alternative in selected patients not eligible or in the waiting list for heart transplantation, since $40.2 \%$ of these patients eventually underwent cardiac transplantation after LVAD implantation. Importantly, patients receiving a rescue LVAD implantation did not experience a higher rate of LVAD-related complications during follow-up. Indeed, $50 \%$ of patients in both groups developed LVAD-related complications, slightly more than the $30 \%$ complications-free rate at one year described in the literature (10-12), a difference probably explained by different population characteristics among studies.

In our study, we show that the occurrence of SCA prior to LVAD and any combined cardiac surgery during LVAD implantation are 2 independent predictors of post-operative mortality in this population. It has been extensively described that the occurrence of SCA is associated with poor outcomes, with only 1 to $12.4 \%$ of survival to hospital discharge in overall population (13). In our study, $38.4 \%$ of 
patients with a rescue LVAD implantation experienced a SCA in the 30-days prior to the surgery and a large proportion of these patients received a temporary mechanical support prior to LVAD, suggesting a high hemodynamic instability during the pre-operative period. Indeed, SCA leads to inflammatory cascade, coagulopathy phenomena and multiple organ failure (14). This precarious situation potentially impacts the post-operative survival. This result is supported by previous work showing that cardiopulmonary resuscitation at the time of mechanical cardiac support implantation increased by 6 -fold the risk of mortality (4). We also showed that any combined surgery during rescue LVAD implantation increased postoperative mortality. Previous works demonstrated that longer cardiopulmonary bypass duration was associated with lower post-operative survival (15-17). Similarly, it was shown that patients scheduled for concomitant cardiac surgery with HeartMate II implantation doubled their post-operative mortality rates at 30 days (18). Lastly, patients requiring a combined surgery to LVAD usually have more complex cardiac disease leading to higher rates of post-operative injuries.

This study brings important information about LVAD candidates' selection in patients with newly diagnosed severe cardiomyopathy requiring a rescue LVAD implantation. Indeed, these patients remain challenging to manage since they are frequently implanted with temporary mechanical support and under mechanical ventilation with deep sedation, making difficult any pre-operative discussion about other advanced therapeutic options. For patients not eligible to heart transplantation, the hemodynamic compromise despite the use of temporary mechanical support calls for consideration of a rescue LVAD implantation which represents a major challenging decision. We show that these LVAD candidates experience a relatively low post-operative mortality, no higher risk of device related complications during 
follow-up and high proportion to be heart transplanted. However, patients requiring a rescue LVAD for a recently diagnosed cardiomyopathy should be carefully selected and the decision to combine a surgical procedure during pump implantation should be discussed.

Our observational study has some limitations, including its retrospective design, which may have affected the results. Furthermore, many French patients are in advanced cardiogenic shock at the time of LVAD implantation, suggesting that our population is probably sicker than U.S. patients at time of implantation. Thus, our results cannot necessarily be extended to other populations. Moreover, we did not collect hemodynamic data that limit an accurate description. Furthermore, patients with recently diagnosed cardiomyopathy had probably less physical deconditioning than remotely cardiomyopathy, potentially explaining better outcomes after LVAD implantation but we cannot provide these information. Lastly, the use of old LVAD generation may not reflect our current practice with the implantation of the HeartMate III pump.

Our study demonstrated that rescue LVAD implantation for recently diagnosed cardiomyopathy is common. These LVAD candidates experience a relatively low post-operative mortality and many of them are eventually heart transplanted during follow-up. Patients with a history of SCA and those requiring a combined cardiac surgery during LVAD implantation are at higher risk of mortality.

Acknowledgement: This research was supported in part by the French Federation of Cardiology.

Funding: This research was supported in part by the French Federation of Cardiology 


\section{Credit Authors Statement}

Elisabeth Chen, MD, = Conceptualization, Writing - Review \& Editing

Nicolas Nesseler, MD, PhD, = Conceptualization, Writing - Review \& Editing

Raphaël P. Martins, MD, PhD, = Conceptualization, Writing - Review \& Editing

Céline Goéminne, MD, = Writing - Review \& Editing

André Vincentelli, MD, $\mathrm{PhD}=$ Writing - Review \& Editing

Clément Delmas $\mathrm{MD},=$ Writing - Review \& Editing

Jean Porterie, $\mathrm{MD}=$ Writing - Review \& Editing

Karine Nubret, MD, = Writing - Review \& Editing

Mathieu Pernot, $\mathrm{MD}=$ Writing - Review \& Editing

Michel Kindo, $\mathrm{MD}, \mathrm{PhD}=$ Writing - Review \& Editing

Tam Hoang Minh, MD= Writing - Review \& Editing

Philippe Gaudard, MD= Writing - Review \& Editing

Philippe Rouvière, $\mathrm{MD}=$ Writing - Review \& Editing

Magali Michel, $\mathrm{MD}=$ Writing - Review \& Editing

Thomas Sénage, $\mathrm{MD}=$ Writing - Review \& Editing

Aude Boignard, $\mathrm{MD}=$ Writing - Review \& Editing

Olivier Chavanon, MD, $\mathrm{P}=$ Writing - Review \& Editing

Constance Verdonk, $\mathrm{MD}=$ Writing - Review \& Editing

Marylou Para, MD=Investigation

Edeline Pelcé, MD = Investigation

Vlad Gariboldi, $\mathrm{MD}, \mathrm{PhD}=$ Writing - Review \& Editing

Matteo Pozzi, MD= Writing - Review \& Editing

Guillaume Baudry, MD= Writing - Review \& Editing

Pierre-Yves Litzler, MD = Writing - Review \& Editing

Frédéric Anselme, $\mathrm{MD}=$ Writing - Review \& Editing

Katrien Blanchart, $\mathrm{MD}=$ Writing - Review \& Editing

Gerard Babatasi, $\mathrm{MD}, \mathrm{PhD}=$ Writing - Review \& Editing

Fabien Garnier, $\mathrm{MD}=$ Writing - Review \& Editing

Marie Bielefeld, $\mathrm{MD}=$ Writing - Review \& Editing

Costin Radu, $\mathrm{MD}=$ Writing - Review \& Editing

Nicolas Lellouche, $\mathrm{MD}, \mathrm{PhD}=$ Writing - Review \& Editing

Thierry Bourguignon, $\mathrm{MD}=$ Writing - Review \& Editing 
Thibaud Genet $\mathrm{MD}=$ Writing - Review \& Editing

Romain Eschalier, $\mathrm{MD}, \mathrm{PhD}=$ Writing - Review \& Editing

Nicolas D’Ostrevy, MD, = Writing - Review \& Editing

Marie-Cécile Bories, MD = Writing - Review \& Editing

Pierre Baudinaud, $\mathrm{MD}=$ Writing - Review \& Editing

Fabrice Vanhuyse, MD = Writing - Review \& Editing

Hugues Blangy, $\mathrm{MD}=$ Writing - Review \& Editing

Christophe Leclercq, $\mathrm{MD}, \mathrm{PhD}=$ Conceptualization

Erwan Flécher, $\mathrm{MD}, \mathrm{PhD}=$ Conceptualization

Vincent Galand, MD = Conceptualization, Formal analysis, Investigation, Writing - Original Draf 
1. Kirkpatrick JN, Wieselthaler G, Strueber M, Sutton MGSJ, Rame JE. Ventricular assist devices for treatment of acute heart failure and chronic heart failure. Heart 2015;101(14):1091-1096.

2. Ponikowski P, Voors AA, Anker SD, et al. 2016 ESC Guidelines for the diagnosis and treatment of acute and chronic heart failure: The Task Force for the diagnosis and treatment of acute and chronic heart failure of the European Society of Cardiology (ESC), Developed with the special contribution of the Heart Failure Association (HFA) of the ESC. Eur Heart J 2016;37(27):2129-2200.

3. Pawale A, Pinney S, Ashley K, Flynn R, Milla F, Anyanwu AC. Implantable left ventricular assist devices as initial therapy for refractory postmyocardial infarction cardiogenic shock. Eur J Cardiothorac Surg 2013;44(2):213-216.

4. Takayama H, Truby L, Koekort M, Uriel N, Colombo P, Mancini DM, Jorde UP, Naka Y. Clinical outcome of mechanical circulatory support for refractory cardiogenic shock in the current era. J Heart Lung Transplant 2013;32(1):106111.

5. Pawale A, Schwartz Y, Itagaki S, Pinney S, Adams DH, Anyanwu AC. Selective implantation of durable left ventricular assist devices as primary therapy for refractory cardiogenic shock. J Thorac Cardiovasc Surg 2018;155(3):1059-1068.

6. Galand V, Flécher E, Auffret V, Boulé S, Vincentelli A, Dambrin C, Mondoly P, Sacher $F$, Nubret $K$, Kindo $M$, Cardi T, Gaudard $P$, Rouvière $P$, Michel $M$, Gourraud JB, Defaye P, Chavanon O, Verdonk C, Ghodbane W, Pelcé E, Gariboldi V, Pozzi M, Obadia JF, Litzler PY, Anselme F, Babatasi G, Belin A, Garnier F, Bielefeld M, Hamon D, Radu C, Pierre B, Bourguignon T, Eschalier R, D'Ostrevy N, Bories MC, Marijon E, Vanhuyse F, Blangy H, Verhoye JP, Leclercq C, Martins RP; ASSIST-ICD Investigators. Predictors and Clinical Impact of Late Ventricular Arrhythmias in Patients With Continuous-Flow Left Ventricular Assist Devices. JACC: Clinical Electrophysiology 2018;4(9):1166-1175. 
7. Kurmani S, Squire I. Acute Heart Failure: Definition, Classification and Epidemiology. Curr Heart Fail Rep 2017;14(5):385-392.

8. Bahit MC, Kochar A, Granger CB. Post-Myocardial Infarction Heart Failure. J Am Coll Cardiol HF 2018;6(3):179-186.

9. Spinar J, Parenica J, Vitovec J, et al. Baseline characteristics and hospital mortality in the Acute Heart Failure Database (AHEAD) Main registry. Crit Care 2011;15(6):R291.

10. Kirklin JK, Naftel DC, Kormos RL, Stevenson LW, Pagani FD, Miller MA, Baldwin JT, Young JB. Fifth INTERMACS annual report: Risk factor analysis from more than 6,000 mechanical circulatory support patients. J Heart Lung Transplantat 2013;32(2):141-156.

11. Kirklin JK, Pagani FD, Kormos RL, Stevenson LW, Blume ED, Myers SL, Miller MA, Baldwin JT, Young JB, Naftel DC. Eighth annual INTERMACS report: Special focus on framing the impact of adverse events. The Journal of Heart and Lung Transplantation 2017;36(10):1080-1086.

12. Adesiyun TA, McLean RC, Tedford RJ, Whitman GJR, Sciortino CM, Conte JV, Shah AS, Russell SD. Long-term follow-up of continuous flow left ventricular assist devices: complications and predisposing risk factors. Int $J$ Artif Organs $2017 ; 40(11): 622-628$.

13. Wong CX, Brown A, Lau DH, Chugh SS, Albert CM, Kalman JM, Sanders P. Epidemiology of Sudden Cardiac Death: Global and Regional Perspectives. Heart, Lung and Circulation 2019;28(1):6-14.

14. Mongardon N, Bouglé A, Geri G, Daviaud F, Morichau-Beauchant T, Tissier R, Dumas F, Cariou A. Pathophysiology and management of post-cardiac arrest syndrome. Annales Françaises d'Anesthésie et de Réanimation 2013;32(11):779-786. 
15. Galand V, Flécher E, Auffret V, Pichard C, Boulé S, Vincentelli A, Rollin A, Mondoly P, Barandon L, Pernot M, Kindo M, Cardi T, Gaudard P, Rouvière P, Sénage T, Jacob N, Defaye P, Chavanon O, Verdonk C, Ghodbane W, Pelcé E, Gariboldi V, Pozzi M, Obadia JF, Savouré A, Anselme F, Babatasi G, Belin A, Garnier F, Bielefeld M, Hamon D, Lellouche N, Pierre B, Bourguignon T, Eschalier R, D'Ostrevy N, Bories MC, Marijon E, Vanhuyse F, Blangy H, Verhoye JP, Leclercq C, Martins RP. Early Ventricular Arrhythmias After LVAD Implantation Is the Strongest Predictor of 30-Day Post-Operative Mortality. JACC: Clinical Electrophysiology 2019;5(8):944-954.

16. Salis S, Mazzanti VV, Merli G, Salvi L, Tedesco CC, Veglia F, Sisillo E. Cardiopulmonary Bypass Duration Is an Independent Predictor of Morbidity and Mortality After Cardiac Surgery. Journal of cardiothoracic and vascular anesthesia 2008;22:814-822.

17. Akin S, Soliman O, de By TMMH, Muslem R, Tijssen JGP, Schoenrath F, Meyns B, Gummert JF, Mohacsi P, Caliskan K; EUROMACS investigators. Causes and predictors of early mortality in patients treated with left ventricular assist device implantation in the European Registry of Mechanical Circulatory Support (EUROMACS). Intensive Care Med 2020;46(7):1349-1360.

18. Pal JD, Klodell CT, John R, Pagani FD, Rogers JG, Farrar DJ, Milano CA; HeartMate II Clinical Investigators. Low Operative Mortality With Implantation of a Continuous-Flow Left Ventricular Assist Device and Impact of Concurrent Cardiac Procedures. Circulation 2009;120(11_suppl_1):S215-9. 


\section{Figure legends}

Figure 1: Cardiomyopathy etiology among the patients receiving a LVAD for a recently diagnosed cardiomyopathy

Figure 2: Causes of death in the post-operative period among patients with recently diagnosed cardiomyopathies

Figure 3: Survival rates by number of predictors of post-operative mortality among patients with recently diagnosed cardiomyopathies

Figure 4: Comparison of survival rates after LVAD implantation in patients with a recently or a remotely diagnosed cardiomyopathy, over the 30 days post-operative days (A) and after hospital discharge (B). 
Figure 1

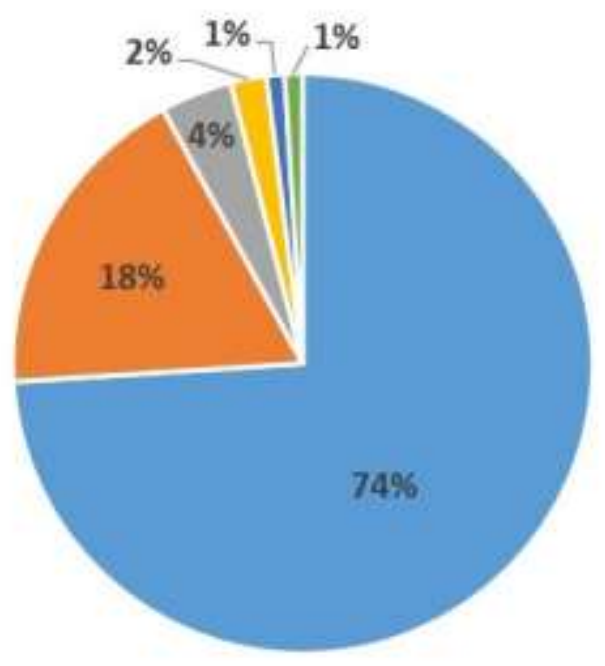

\author{
= Ischemic \\ = Idiopathic \\ " Myocarditis \\ = Valvular disease \\ = Beta-blocker drug \\ intoxication \\ = Hypertrophic \\ cardlomyopahty
}

Figure 2

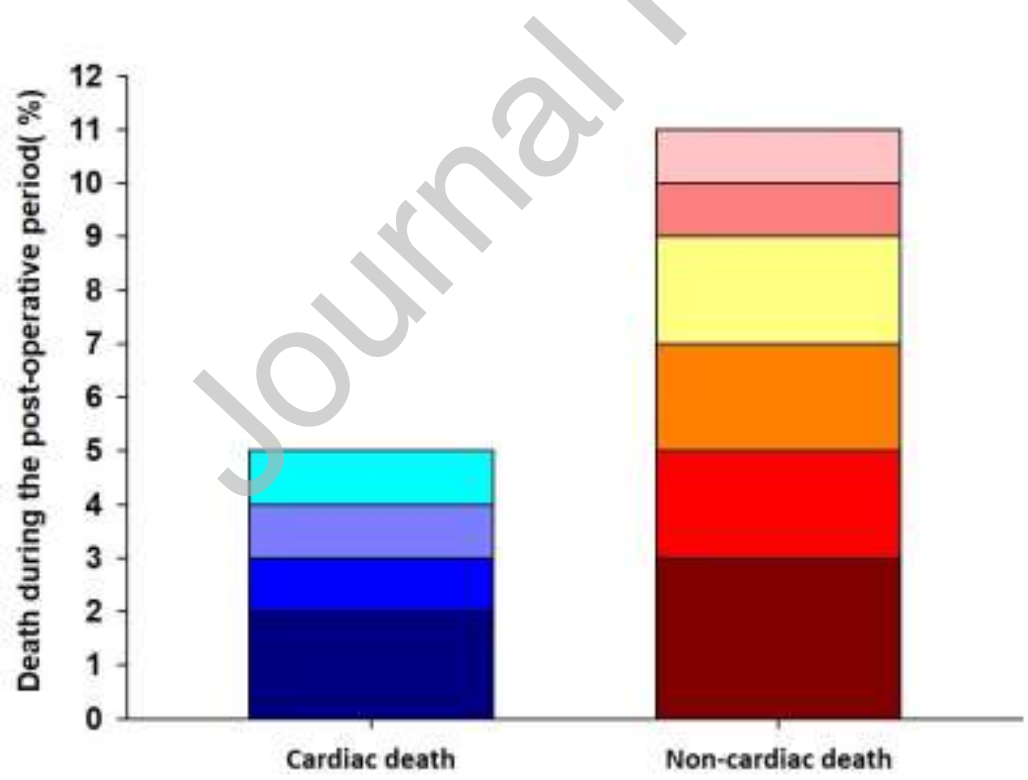

Electrical storm

Right ventricular failure

Hemorrhagic shock

Sepsis

Multi-organ failure

Respiratory failure

Cerebral bleeding

Mesenteric ischemia 
Figure 3

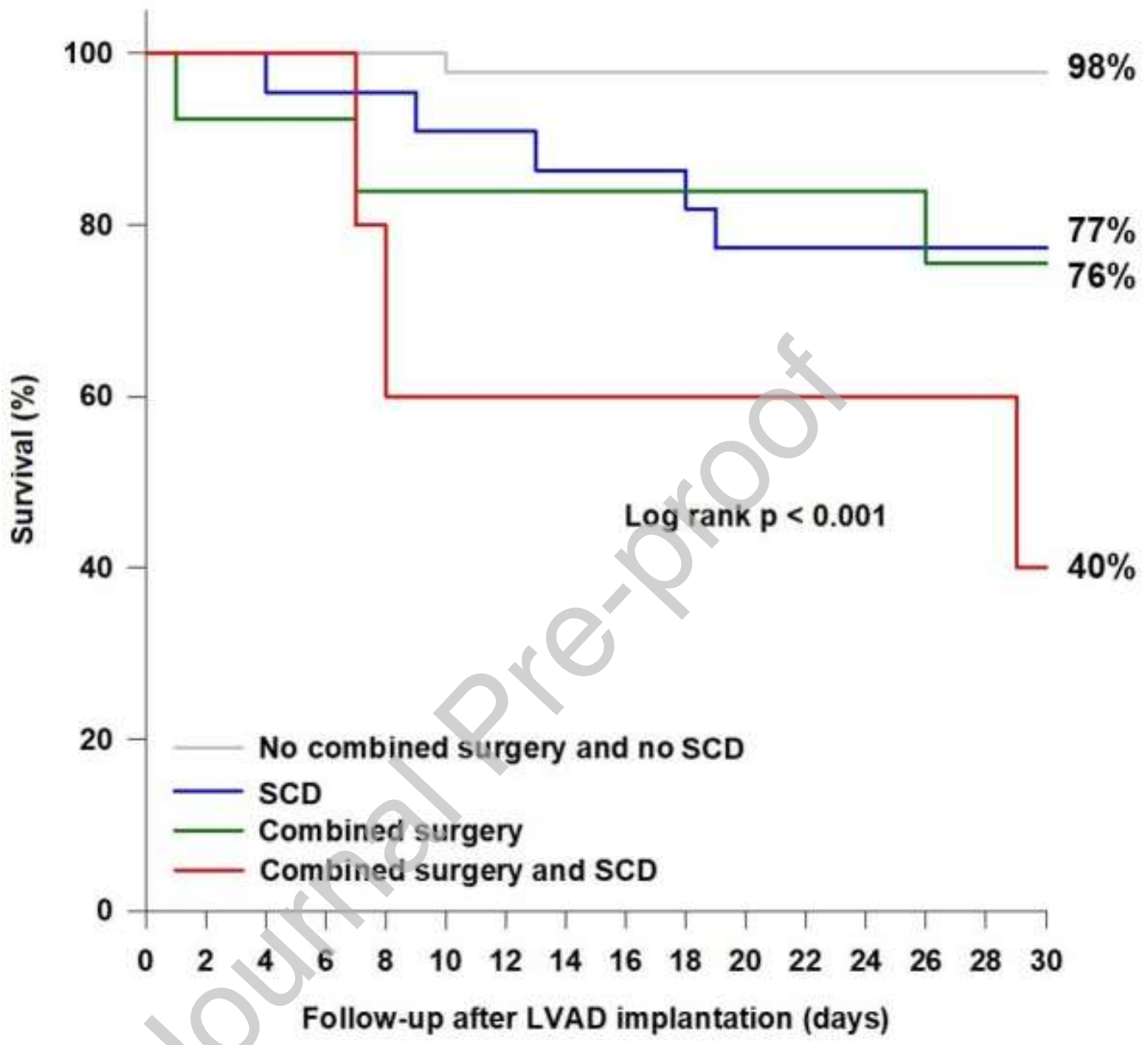




\section{Figure 4}
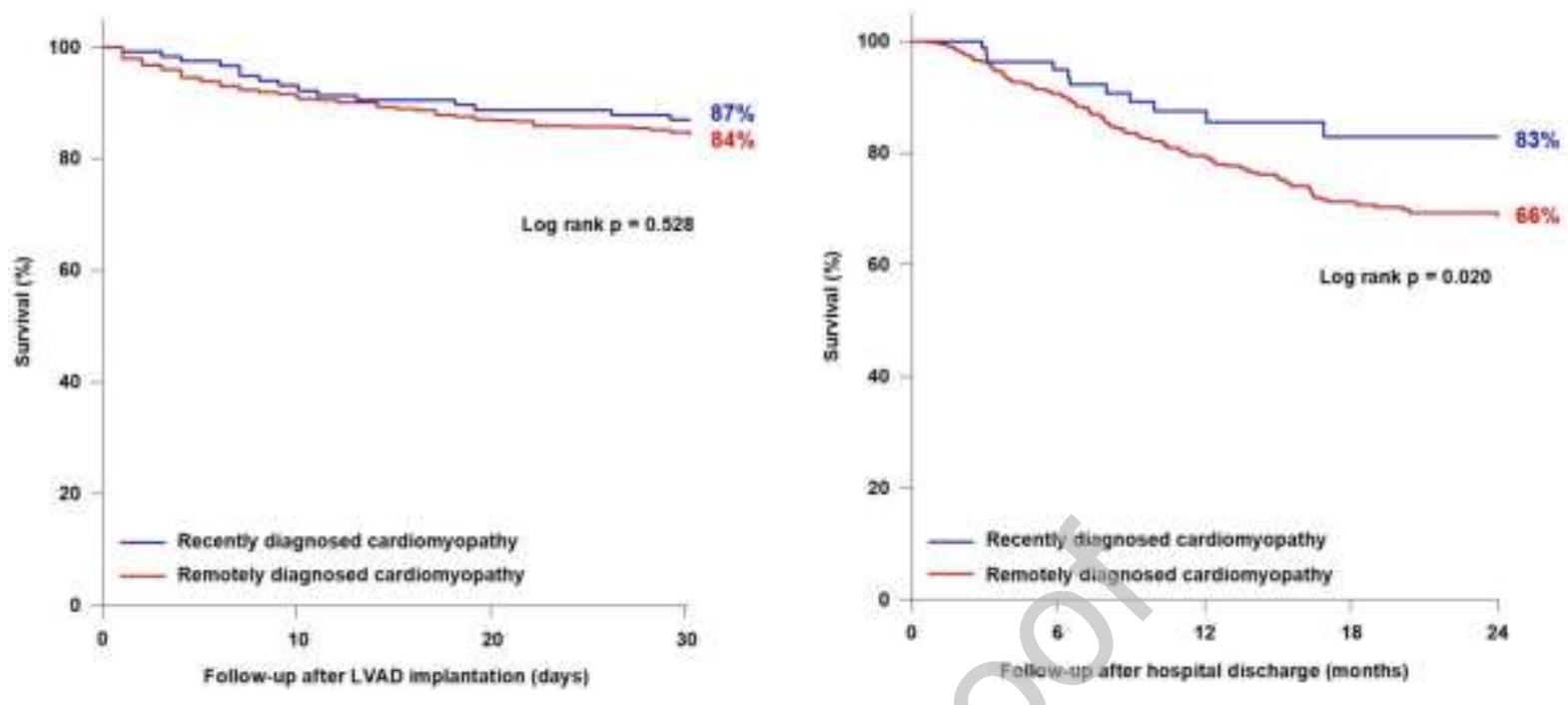
Table 1: Baseline characteristics among patients with recently or remotely diagnosed cardiomyopathies.

Variable

LVAD implantation after diagnosis of

p-Value cardiomyopathy

$\begin{array}{lc}<30 \text { days } & >30 \text { days } \\ (n=117) & (n=535)\end{array}$

Ages, (years)

Men

Body mass index, $\left(\mathrm{kg} / \mathrm{m}^{2}\right)$

Hypertension

Diabetes mellitus

Heart failure etiology

- Ischemic

- Idiopathic

- Other

Heart failure duration, (months)

LVEDD prior to LVAD, (mm)

LVEF prior to LVAD, (\%)

Sudden cardiac arrest prior to

LVAD

Prior supra-ventricular arrhythmia

ICD prior to LVAD insertion

CRT prior to LVAD insertion

Temporary mechanical

circulatory support prior to

LVAD

- Impella
$55.2(46.9-61.4)$

$96(82 \%)$

24.5 (21.6-26.4)

33 (28\%)

$23(20 \%)$

87 (74\%)

$21(18 \%)$

$9(8 \%)$

$0.5(0.3-0.8)$

60.7 (53.3-66.9)

$<0.001$

465 (86\%)

0.219

25.5 (22.8-28.4) $<0.001$

$200(37 \%)$

$131(24 \%)$

0.077

0.320

325 (61\%)

157 (29\%)

$53(10 \%)$

91.9 (17.4-193.3)

3)

$<0.001$
$66.0(60.0-71.0)$

70.0 (64.0-76.0)

$<0.001$

$18.8 \pm 8.9$

$20.9 \pm 7.2$

0.003

45(38\%)

$61(11 \%)$ $<0.001$

$18(15 \%)$

$284(53 \%)$

$<0.001$

$2(2 \%)$

401 (75\%)

$<0.001$

$2(2 \%)$

$196(37 \%)$

$<0.001$

$26(22 \%)$

$38(7 \%)$

$<0.001$ 
- Intra-aortic balloon pump

- Extra-corporeal life support

- Creatinine, ( $\mu \mathrm{mol} / \mathrm{L})$

- Serum sodium, (mmol/L)

- Total bilirubin, ( $\mu \mathrm{mol} / \mathrm{L})$

Type of LVAD

- HeartMate 2

- HeartWare

- Jarvik2000

LVAD indication

- Bridge to transplantation

- Destination therapy

- Bridge to decision / recovery

Surgery combined with LVAD*

Temporary right ECLS during

surgery

Total days in ICU

Total days in hospital
$42(36 \%)$

$66(56 \%)$

105.0 (72.0-142.0)

138.0 (135.0-142.0)

16.7 (10.0-28.0)

$89(76 \%)$

$25(21 \%)$

$3(3 \%)$
$16(3 \%)$

$<0.001$

$70(13 \%)$

$<0.001$

0.020

116.0 (89.0-148.2)

$<0.001$

135.0 (132.0-138.0)

0.556

$16.0(10.0-26.0)$

0.070

$386(72 \%)$

$102(19 \%)$

$47(8 \%)$ $<0.001$

* Surgery combined with LVAD included any additional cardiac intervention increasing the total surgical duration time (i.e. coronary artery bypass grafting, valve replacement/repair, ventricular arrhythmia ablation, foramen oval closure, septal defect closure) 
Table 2: Mid-term outcomes for patients with recently diagnosed cardiomyopathies.

\section{Variable}

LVAD implantation after diagnosis of cardiomyopathy

$<30$ days $>30$ days

$(\mathrm{n}=117)$ $(\mathrm{n}=535)$

Heart transplantation

Total death

Cause of death

$47(40 \%)$

$38(32 \%)$

$152(28 \%)$

0.017

- Cardiovascular

- Non cardiovascular

- Unknown

Any LVAD-related complications

LVAD thrombosis

Stroke

Bleeding

Percutaneous driveline infection

LVAD exchange
$61(52 \%)$

$12(10 \%)$

$15(13 \%)$

$18(15 \%)$

34 (29\%)

$3(3 \%)$
$253(47 \%)$

0.005

0.269

$113(44 \%)$

137 (54\%)

$3(1 \%)$
$30(6 \%)$

0.678

72 (13\%)

0.433

73 (14\%)

0.931

$91(17 \%)$

0.772

137 (26\%)

0.514

0.260 
Table 3: Baseline characteristics between survivors and deceased in the recently diagnosed group

Variable

Recently LVAD implantation after

p-Value

diagnosis of cardiomyopathy

$\begin{array}{cc}\text { 30-days post- } & \text { Alive at 30-days } \\ \text { operative mortality } & \text { post-operative }\end{array}$

$(n=16)$

$(\mathrm{n}=101)$

\begin{tabular}{|c|c|c|c|}
\hline Ages, (years) & $57.0(51.4-66.3)$ & $54.0(45.2-61.1)$ & 0.095 \\
\hline Men & $14(87 \%)$ & $82(82 \%)$ & 0.794 \\
\hline Body mass index, $\left(\mathrm{kg} / \mathrm{m}^{2}\right)$ & $24.0 \pm 3.2$ & $25.5 \pm 2.8$ & 0.071 \\
\hline Hypertension & $7(44 \%)$ & $26(26 \%)$ & 0.235 \\
\hline Diabetes mellitus & $1(6 \%)$ & $22(22 \%)$ & 0.265 \\
\hline Heart failure etiology & & & 0.362 \\
\hline - Ischemic & $(81 \%)$ & $74(73 \%)$ & \\
\hline - Idiopathic & $(6 \%)$ & $20(20 \%)$ & \\
\hline - Other & $2(12 \%)$ & $7(7 \%)$ & \\
\hline Heart failure duration, (days) & $19.5(13.0-23.5)$ & $15.0(10.0-23.2)$ & 0.482 \\
\hline LVEDD prior to LVAD, (mm) & $62.0(59.5-65.0)$ & $66.0(60.2-71.0)$ & 0.231 \\
\hline LVEF prior to LVAD, (\%) & $15.0(10.0-20.0)$ & $20.0(15.0-25.0)$ & 0.045 \\
\hline Sudden cardiac arrest prior to LVAD & $11(69 \%)$ & $34(34 \%)$ & 0.016 \\
\hline Prior supra-ventricular arrhythmia & $1(6 \%)$ & $17(17 \%)$ & 0.482 \\
\hline \multicolumn{4}{|l|}{ Temporary mechanical circulatory } \\
\hline support prior to LVAD & $15(94 \%)$ & $72(83 \%)$ & 0.109 \\
\hline - Impella & $6(37 \%)$ & $20(20 \%)$ & 0.208 \\
\hline - Intra-aortic balloon pump & $5(31 \%)$ & $37(37 \%)$ & 0.891 \\
\hline - Extra-corporeal life support & $11(69 \%)$ & $55(54 \%)$ & 0.424 \\
\hline - Creatinine, $\mu \mathrm{mol} / \mathrm{L}$ & $137.5(118.5-246.0)$ & $98.0(70.5-131.0)$ & 0.006 \\
\hline - Serum sodium, mmol/L & $139.0 \pm 6.1$ & $138.0 \pm 6.2$ & 0.529 \\
\hline - Total bilirubin, $\mu \mathrm{mol} / \mathrm{L}$ & $21.0(9.2-37.0)$ & $16.4(10.0-27.7)$ & 0.723 \\
\hline Type of LVAD & & & 0.484 \\
\hline - HeartMate 2 & $11(69 \%)$ & $78(77 \%)$ & \\
\hline
\end{tabular}




\begin{tabular}{lccc}
\hline - HeartWare & $5(31 \%)$ & $20(20 \%)$ & \\
- Jarvik2000 & $0(0 \%)$ & $3(3 \%)$ & $<0.001$ \\
\hline LVAD indication & & & \\
- Bridge to transplant & $5(31 \%)$ & $18(77 \%)$ & \\
- Destination therapy & $6(37 \%)$ & $4(4 \%)$ & 0.023 \\
- Other & $5(31 \%)$ & $12(12 \%)$ & 0.718 \\
\hline Surgery combined with LVAD & $6(37 \%)$ & $12(12 \%)$ & 0.478 \\
\hline Temporary right ECLS during & $3(19 \%)$ & & \\
surgery & & $20(20 \%)$ & \\
\hline Early ventricular arrhythmia (<30 & $5(31 \%)$ & & \\
days) & & &
\end{tabular}


Table 4: Multivariate analysis

Variable

B coefficient

Multivariable HR

p-value

(95\% Cl)

\begin{tabular}{llll}
\hline LVEF $>\mathbf{2 0} \%$ & -0.930 & $0.39(0.073-2.14)$ & 0.281
\end{tabular}

Sudden cardiac arrest prior to LVAD

2.470

$11.82(1.95-71.69)$

0.007

Creatinine, ( $\mu \mathrm{mol} / \mathrm{L})$

0.011

$1.01(0.99-1.02)$

0.101

Destination therapy

0.983

$2.67(0.42-16.79)$

0.295

Cardiac surgery combined with LVAD

1.839

$6.29(1.06-37.41)$

0.043 